\title{
Production of Intersectional Hybrids between Colchicine-induced Tetraploid Shashanbo (Vaccinium bracteatum) and Highbush Blueberry 'Spartan'
}

\author{
Hirotoshi Tsuda \\ Interdisciplinary Graduate School of Agriculture and Engineering, University of Miyazaki, 1-1, \\ Gakuenkibanadai-Nishi, Miyazaki 889-2192, Japan \\ Hisato Kunitake ${ }^{1}$ and Mai Yamasaki \\ Faculty of Agriculture, University of Miyazaki, 1-1, Gakuenkibanadai-Nishi, Miyazaki 889-2192, \\ Japan \\ Haruki Komatsu \\ School of Agriculture, Tokai University, 5435, Minamiaso, Aso, Kumamoto 869-1404, Japan \\ Katsunori Yoshioka \\ P-DESTM Corporation, 1254, Chitoku, Tanushimaru, Kurume, Fukuoka 839-1214, Japan
}

\begin{abstract}
AdDitional INDEX words. chromosome, genetic resources, pollen stainability, polyploidy, Vaccinium corymbosum, wide hybridization

ABSTRACT. With crosses between colchicine-induced tetraploid shashanbo (Vaccinium bracteatum section Bracteata) and tetraploid highbush blueberry 'Spartan' (Vaccinium corymbosum section Cyanococcus), intersectional hybrids were produced. The hybridity of these plants was confirmed based on DNA markers and morphological characteristics. The morphological characteristics, blooming date, and ripening period of the hybrids were intermediate between those of the parents. Ploidy analyses by flow cytometry and chromosome counting revealed that these hybrids were tetraploid. Four hybrids set fruit in the field and these two hybrids showed high pollen stainability. It was noteworthy that fruit of two hybrids had high soluble solids concentration compared with 'Spartan' and the fruit pulp of the hybrids was tinged with red as shashanbo. These hybrids could be useful in breeding new cultivars with high sugar content, abundant phytochemicals, extensive environmental adaptability as well as late flowering and fruit maturity.
\end{abstract}

In Japan, 19 native species of the genus Vaccinium are distributed from Hokkaido to the Kyushu region (Yamazaki, 1989). The diploid evergreen shrub shashanbo is distributed from the east to the west of Japan, and its edible berries are commonly harvested and processed for local foods (Atkinson et al., 1995; Hirai et al., 2010; Iwagaki et al., 1977). Shashanbo blooms from May to June and produces numerous small, dark blue berries that ripen from September to December. This shrub species is of interest to blueberry (Vaccinium sp.) breeders for several reasons; for example, it has a wide and deep root system, which makes the plants drought-tolerant, and it can grow well in higher $\mathrm{pH}$ soils compared with other species in the section Cyanococcus (Karizumi, 1979; Kunitake et al., 2006; Luby et al., 1991). However, cultivated highbush blueberry requires acidic soil and has shallow, fibrous roots that require continuous moisture in the top $1 \mathrm{~m}$ of soil (Lyrene, 2011). Therefore, shashanbo might be used as a good germplasm source to breed highbush blueberry in that they are more adaptable in a broad range of environmental conditions.

Received for publication 23 Apr. 2013. Accepted for publication 5 June 2013 This research was financially supported by the Sasakawa Scientific Research Grant from The Japan Science Society.

We are grateful to Dr. Masahiro Mii of the Graduate School of Horticulture, Chiba University, for his advice and critical reading of this manuscript.

${ }^{1}$ Corresponding author. E-mail: hkuni@cc.miyazaki-u.ac.jp.
However, there have been no reports on the hybridization of blueberry with shashanbo.

Intersectional crosses have successfully produced several hybrids in Vaccinium (Ballington, 1980, 2001; Darrow and Camp, 1945; Lyrene, 2011; Rousi, 1963), but our previous attempts to cross diploid shashanbo with tetraploid highbush blueberry cultivars have not been successful ( $\mathrm{H}$. Tsuda, unpublished data). The failure might be attributable in part to the triploid block, which is strong in Vaccinium (Darrow et al., 1944) along with other genetic crossing barriers between the sections Bracteata and Cyanococcus. In attempting to cross section Cyanococcus with species of other sections, blueberry breeders typically have used plants with the same chromosome numbers to avoid the ploidylevel barrier in addition to other genetic barriers, which might separate the sections (Lyrene and Ballington, 1986). The hybridization barrier imposed by differences in the ploidy level in blueberry has been overcome by using clones that produce substantial numbers of $2 \mathrm{n}$ gametes and colchicine-induced polyploids (Lyrene, 2011). In our previous study, we have succeeded to obtain several tetraploid shashanbo plants by colchicine treatment $(\mathrm{H}$. Tsuda, unpublished data).

The objectives of the present study were as follows: 1) to produce intersectional hybrids from the crosses between colchicine-induced tetraploid shashanbo and highbush blueberry 'Spartan'; 2) to confirm the hybridity and ploidy level of putative hybrids using morphological observation, molecular 
markers, flow cytometry, and chromosome counts; and 3) to compare plant morphological characteristics and pollen stainability of these plants and their parents.

\section{Materials and Methods}

Plant materials. The seeds collected from wild-type shashanbo at Yame city, Fukuoka prefecture, Japan, were sterilized with sodium hypochlorite solution of $2 \%$ available chlorine for 7 min, sowed on MW medium [a mixture of equal parts of MS (Murashige and Skoog, 1962) and WPM (Lloyd and McCown, 1980)] (Tetsumura et al., 2008) supplemented with $0.05 \%$ colchicine but without plant growth regulators in $100-\mathrm{mL}$ Erlenmeyer flask. Twenty days later, the seeds were transferred onto the MW medium without colchicine and for promoting the growth. One month after acclimatization, colchicine-induced tetraploid shashanbo (VB4x-1 and VB4x-2) were selected by flow cytometry, chromosome counting, and morphological characteristics and then were cultivated in the greenhouse (H. Tsuda, unpublished data). In early June 2009, 89 flowers of VB4x-1 and 14 flowers of VB4x-2 were hand-pollinated with the pollen of tetraploid highbush blueberry 'Spartan'. Thirty-four fruit [29 fruit (VB4x-1), five fruit (VB4x-2)] from pollinated flowers were harvested at maturity in Nov. 2009 and 104 developed seeds [81 seeds (VB4x-1), 23 seeds (VB4x-2)] were collected from all fruit harvested. The seeds were placed on moistened peatmoss and kept at room temperature. After germination, the seedlings were transplanted onto peatmoss in pots and grown in a greenhouse at Kibana Agriculture Science Station of the University of Miyazaki, Miyazaki, Japan. We selected five deciduous seedlings (JM1 to JM5) in 2010, and they were grafted onto rootstock of rabbiteye blueberry 'Homebell' (Vaccinium virgatum) in Jan. 2011 to promote the growth of plants. Seed parents of JM1 to JM4 were VB4X-1, whereas VB4x-2 was used as a seed parent for JM5. Analysis and observation of these five putative hybrids except for primary growth observations were conducted 1 to 2 years after grafting.

Morphological Characteristics. We investigated the morphological characteristics of the five putative hybrids and their parents. In early Oct. 2011, the leaf length, leaf width, and leaf weight of fully expanded leaves were measured. Furthermore, glandular protuberances on the midrib of the undersurface of the leaf were confirmed. In late Dec. 2011, the leaf color was determined on the surface of fully mature symptomless leaves using a spectrophotometer (NF333; Nippon Denshoku, Tokyo, Japan) calibrated with a white standard tile. Leaves were collected and measured at the peak of the browning period of 'Spartan' when the leaf color showed the brightest red. The flowers of putative hybrids (JM1, JM3, JM4, and JM5) bloomed 2 years after grafting. In Apr. to May 2012, we measured the morphological characteristics of flowers in full bloom (corolla length, corolla width, shape index of corolla, corolla aperture, pedicel length, style length, and number of florets). Fruit characteristics (fruit weight, fruit diameter, fruit height, shape index, soluble solids concentration, seed number, and color of peel) were observed during the maturation period in 2012. At least 10 leaves, flowers, and fruit were collected from each putative hybrid and their parents and were used for observation of morphological characteristics. Flowers of putative hybrids were pollinated with pollen from highbush blueberry cultivars for fruit observations.

Molecular MARKer ANALySES. Total DNA was extracted from young leaves of each plant following the method described by Doyle and Doyle (1987). The total DNA was used for analyses of nuclear and cytoplasmic DNA, including random amplified polymorphic DNA (RAPD) and cleaved amplified polymorphic sequence (CAPS) analyses.

RAPD analysis of nuclear DNA was performed by the method of Williams et al. (1990) with modifications. Polymerase chain reaction (PCR) was carried out with 40 Operon random 10-mer primers (OPA1-OPA20 and OPH1-OPH20) (Operon Technologies, Alameda, CA) using the My Cycler ${ }^{\mathrm{TM}}$ Thermal Cycler (BioRad Laboratories, Hercules, CA). The reaction products were electrophoresed on $1.0 \%$ agarose gels containing $0.1 \mu \mathrm{g} \cdot \mathrm{mL}^{-1}$ ethidium bromide (IBI Scientific, Peosta, IA) and subsequently photographed under ultraviolet light $(360 \mathrm{~nm})$. For each combination of sample and primers, PCR was carried out twice, and only stable polymorphisms were analyzed.

CAPS analysis was performed for several chloroplast (cp) and mitochondrial $(\mathrm{mt})$ non-coding regions. For cpDNA analysis, one primer pair of $\operatorname{trnK}-3914 F-\operatorname{trnK}-2 R$ was used for amplification following the methods of Cheng et al. (2002) and Ureshino and Miyajima (2002). For mtDNA analysis, three primer pairs of 18SrRNA-5SrRNA, nad4exon1-nad4exon 2 , and nad5/1-nad5/2 $r$ were used for amplification following the methods of Cheng et al. (2002) and Dumolin-Lapegue et al. (1997). The PCR products were digested with several restriction endonucleases and then electrophoresed under the same protocol as that used in our RAPD analysis.

Confirmation of PLOIDY LEVEL. Immature leaves were collected from each of the seedlings and their parents for flow cytometry. Leaf segments of $\approx 1 \mathrm{~cm}^{2}$ were chopped with a razor blade and treated for $5 \mathrm{~min}$ with $1 \mathrm{~mL}$ buffer solution containing $10 \mu \mathrm{g} \cdot \mathrm{L}^{-1}$ RNase (Sigma, St. Louis, MO), 1.0\% (v/v) Triton X-100 (Nacalai Tesque, Kyoto, Japan), 5.0\% (v/v) polyvinylpyrrolidone (PVP10; Sigma), $50 \mathrm{~mm} \mathrm{Na} \mathrm{SO}_{3}$, and $50 \mathrm{~mm}$ Tris$\mathrm{HCl}$ at $\mathrm{pH} 7.5$ according to the preparation method of Yahata et al. (2005) with some modification. Samples were filtered using a 20- $\mu \mathrm{m}$ filter (Cell Trics; Partec, Münster, Germany) and stained with $25 \mu \mathrm{g} \cdot \mathrm{L}^{-1}$ propidium iodide. The relative fluorescence of the total DNA was measured for each nucleus using a flow cytometry system (Cell Laboratory Quanta ${ }^{\mathrm{TM}}$ SC MPL System; Beckman Coulter, Fullerton, CA) equipped with a $488-\mathrm{nm}$ solid-state laser. Nuclei of Citrus 'Tahiti Lime' (1.17 pg/2C) were used as an internal standard (Ollitraut et al., 1994). The relative nuclear DNA content of each sample was measured three times for statistical analysis (Tukey's multiple range test).

For chromosome observation, shoot tips ( $\approx 3$ to $5 \mathrm{~mm}$ long) were excised from the plants, immersed in $2 \mathrm{~mm} 8$-hydroxyquinoline for $2 \mathrm{~h}$ at $25^{\circ} \mathrm{C}$, and fixed in a mixed solution of ethanol and acetic acid $(3: 1)$ for $20 \mathrm{~min}$ at $25^{\circ} \mathrm{C}$. Enzymatic maceration and air-drying were performed according to the method of Fukui (1996) with some modifications. The chromosome were stained with $2.0 \%$ Giemsa solution (Merck, Darmstadt, Germany) in 1/30 M phosphate buffer ( $\mathrm{pH}$ 6.8) and observed under an optical microscope (BX51; Olympus Optical, Tokyo, Japan) at 400× magnification.

Pollen stainability and Morphology. The pollen of putative hybrids and their parents was collected from the plants and stored at $-40{ }^{\circ} \mathrm{C}$ until it was used for experiments. Pollen stainability was estimated using dry pollen moistened with acetocarmine solution (Nacalai Tesque). Each slide was prepared using pollen from two to three flowers. At least 200 pollen grains were examined in three replicates of the analysis. The pollen stainabiblity was determined as the ratio of well-filled, evenly 
stained pollen grains to total pollen grains examined under a microscope (BX51) at 200× magnification.

\section{Results}

Sixty-six seedlings were obtained from the crosses between colchicineinduced tetraploid shashanbo and highbush blueberry 'Spartan'. Most of these seedlings grew vigorously, and the height of plants reached $\approx 30$ $\mathrm{cm}$ at 1 year after sowing. These hybrids were separated into evergreen or deciduous plants. We compared the morphological characteristics of the five putative hybrids with those of the parents. In the greenhouse, all putative hybrids were highly vigorous with numerous shoots, whereas current shoots of shashanbo and the putative hybrids were tinged with red and those of 'Spartan' were light green. The bark surface on older wood of the putative hybrids was smoother than that of 'Spartan', and the color and patterning were similar to those of shashanbo. The leaf characteristics of the putative hybrids were in some cases similar to those of either parent or intermediate between the two parents in other cases (Table 1; Fig. 1). The leaf length and leaf width of the putative hybrids were intermediate between those of the parents, whereas the leaf weight per unit area of the putative hybrids ( 4.3 to $5.4 \mathrm{mg} \cdot \mathrm{cm}^{-2}$ ) was significantly lighter than that of shashanbo $\left(8.4\right.$ or $\left.9.0 \mathrm{mg} \cdot \mathrm{cm}^{-2}\right)$. Parents 'Spartan' had entire leaves and shashanbo had clear serration, whereas the putative hybrids had serrate leaves but the leaves had smooth edges compared with shashanbo leaves. Shashanbo has glandular protuberances on the midrib of the undersurface of the leaf. The putative hybrids had the same type of midrib as that of shashanbo, but the midrib of 'Spartan' lacked glandular protuberances. At the peak of the browning period of 'Spartan', we observed the leaf color of the putative hybrids. Although the leaf colors of the putative hybrids were highly variable, ranging from brown-green to dark red, shashanbo maintained its green color. The $\mathrm{a}^{*}$ (green-red) values of the leaf surface as determined by the spectrophotometer showed significant differences among the three taxa ('Spartan', putative hybrids, and shashanbo) (Table 1). 'Spartan' plants dropped all

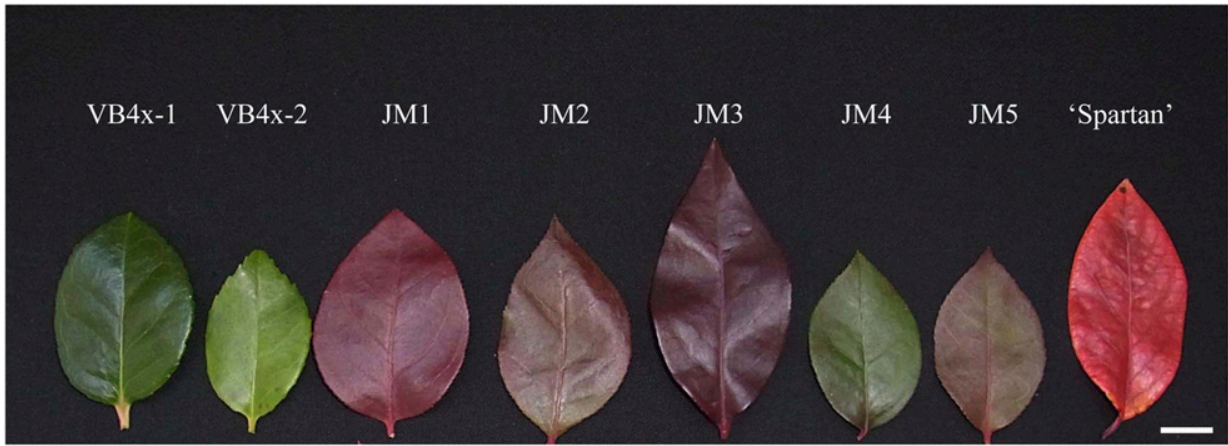

Fig. 1. Characteristics of leaves and leaf browning in the putative intersectional hybrids and their parents in Vaccinium: VB4x-1, VB4x-2 (shashanbo); JM1, JM2, JM3, JM4, JM5 (putative intersectional hybrids); highbush blueberry 'Spartan'. Leaf color was detected by spectrophotometer at the browning period of 'Spartan' (27 Dec. 2011); bar $=20 \mathrm{~mm}$.
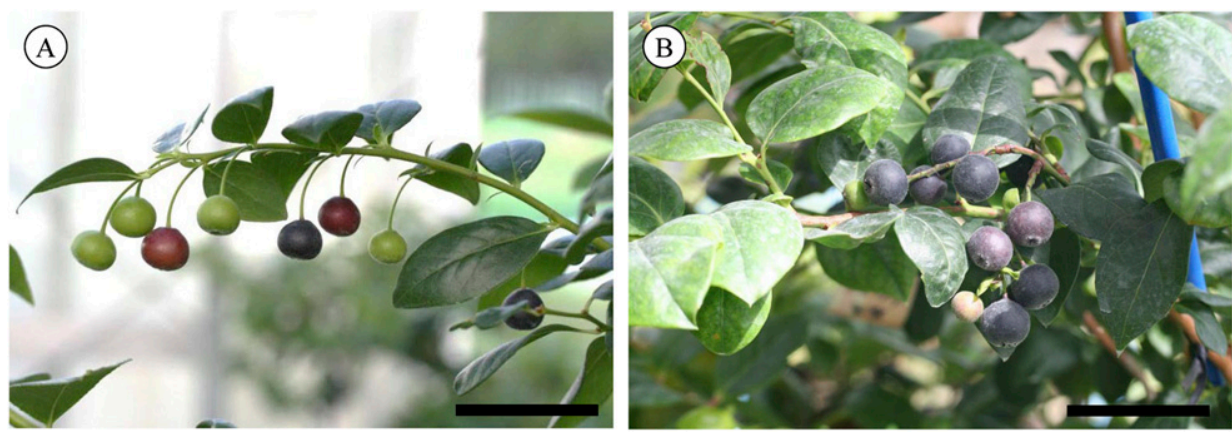

Fig. 2. Maturing fruit of putative intersectional hybrid JM1 in Vaccinium. (A) Inflorescence with large bract (or small leaf). (B) Inflorescence with small bract or no bract; bars $=50 \mathrm{~mm}$.
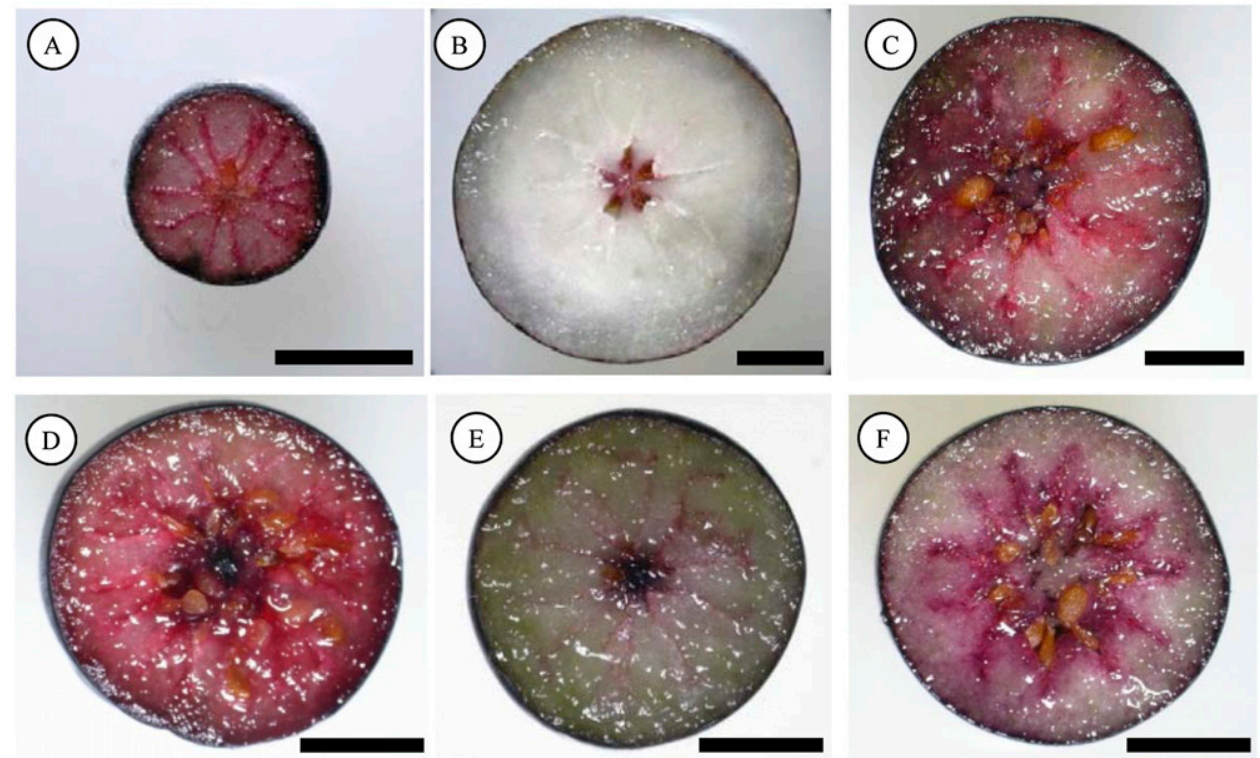

Fig. 3. Comparison of the cross section of fruit in the putative intersectional hybrids and their parents in Vaccinium: (A) VB4x-1 (shashanbo), (B) highbush blueberry 'Spartan', (C-F) putative intersectional hybrids [(C) JM1, (D) JM3, (E) JM4, (F) JM5]; bars = $5 \mathrm{~mm}$.

of their leaves in winter. On the other hand, the leaf colors of putative hybrids changed to red in winter and the putative hybrids shed their leaves completely from winter to early spring. 
Table 1. Comparison of the morphological characteristics of leaves in parents shashanbo and highbush blueberry 'Spartan' and their putative hybrids.

\begin{tabular}{|c|c|c|c|c|c|c|c|}
\hline \multirow[b]{2}{*}{ Strains } & \multicolumn{2}{|c|}{ Leaf blade (mm) } & \multirow{2}{*}{$\begin{array}{c}\text { Leaf blade shape index } \\
\text { (length/width) }\end{array}$} & \multirow{2}{*}{$\begin{array}{c}\text { Leaf wt } \\
\left(\mathrm{mg} \cdot \mathrm{cm}^{-2}\right)\end{array}$} & \multicolumn{3}{|c|}{ Leaf color ${ }^{\mathrm{x}}$} \\
\hline & Length & Width & & & $\mathrm{L}^{*}$ & $a^{*}$ & $\mathrm{~b}^{*}$ \\
\hline \multicolumn{8}{|l|}{ Shashanbo } \\
\hline VB4x-1 & $57.8 \mathrm{~b}-\mathrm{d}^{\mathrm{y}}$ & $37.1 \mathrm{e}$ & $1.6 \mathrm{ab}$ & $8.4 \mathrm{f}$ & $25.8 \mathrm{ab}$ & $-12.8 \mathrm{a}$ & $14.6 \mathrm{cde}$ \\
\hline VB4x-2 & $43.6 \mathrm{a}$ & $28.7 \mathrm{a}$ & $1.5 \mathrm{a}$ & $9.0 \mathrm{f}$ & $34.6 \mathrm{~cd}$ & $-17.5 \mathrm{a}$ & $27.0 \mathrm{f}$ \\
\hline \multicolumn{8}{|c|}{ Putative hybrids ${ }^{\mathrm{z}}$} \\
\hline JM1 & $70.4 \mathrm{e}$ & $43.4 \mathrm{f}$ & $1.6 \mathrm{a}-\mathrm{c}$ & $4.3 \mathrm{a}$ & $28.4 \mathrm{abc}$ & $17.3 \mathrm{e}$ & $6.6 \mathrm{ab}$ \\
\hline JM2 & $62.0 \mathrm{~d}$ & $33.2 \mathrm{~b}-\mathrm{d}$ & $1.9 \mathrm{de}$ & $5.3 \mathrm{~b}-\mathrm{d}$ & $30.8 \mathrm{bcd}$ & $7.1 \mathrm{c}$ & $10.7 \mathrm{bcd}$ \\
\hline JM3 & $74.1 \mathrm{e}$ & $32.9 \mathrm{~b}-\mathrm{d}$ & $2.3 \mathrm{f}$ & $5.3 \mathrm{~b}-\mathrm{e}$ & $24.2 \mathrm{a}$ & $9.7 \mathrm{~cd}$ & $3.2 \mathrm{ab}$ \\
\hline JM4 & $54.8 \mathrm{~b}$ & $31.7 \mathrm{a}-\mathrm{c}$ & $1.7 \mathrm{~cd}$ & $4.8 \mathrm{ab}$ & $32.6 \mathrm{~cd}$ & $-5.7 \mathrm{~b}$ & 14.4 cde \\
\hline JM5 & $55.1 \mathrm{bc}$ & $30.4 \mathrm{ab}$ & $1.8 \mathrm{de}$ & $5.4 \mathrm{~b}-\mathrm{e}$ & $31.6 \mathrm{bcd}$ & $9.2 \mathrm{~cd}$ & $9.3 \mathrm{abc}$ \\
\hline \multicolumn{8}{|c|}{ Highbush blueberry } \\
\hline Spartan & $84.2 \mathrm{f}$ & $39.7 \mathrm{e}$ & $2.1 \mathrm{f}$ & $5.3 \mathrm{bc}$ & $35.7 \mathrm{~d}$ & $43.3 \mathrm{f}$ & $21.0 \mathrm{e}$ \\
\hline
\end{tabular}

${ }^{\mathrm{z}}$ Seed parents of JM1 to JM4 were VB4x-1, whereas VB4x-2 was used as a seed parent for JM5.

${ }^{y}$ Different letters represents significant differences in Tukey's multiple range test, $1 \%$ level.

${ }^{x}$ Leaf color was detected by spectrophotometer at the browning period of 'Spartan' (27 Dec. 2011); L* $=$ lightness-darkness parameter, a* $=$ redgreen parameter, $b^{*}=$ blue-yellow parameter.

Table 2. Comparison of the morphological characteristics of flowers in parents shashanbo and highbush blueberry 'Spartan' and their putative hybrids.

\begin{tabular}{|c|c|c|c|c|c|c|c|}
\hline \multirow[b]{2}{*}{ Strains } & \multicolumn{2}{|c|}{ Corolla $(\mathrm{mm})$} & \multirow{2}{*}{$\begin{array}{l}\text { Corolla shape index } \\
\text { (length/width) }\end{array}$} & \multirow{2}{*}{$\begin{array}{l}\text { Corolla aperture } \\
(\mathrm{mm})\end{array}$} & \multirow{2}{*}{$\begin{array}{l}\text { Style length } \\
(\mathrm{mm})\end{array}$} & \multirow{2}{*}{$\begin{array}{l}\text { Pedicel length } \\
(\mathrm{mm})\end{array}$} & \multirow{2}{*}{$\begin{array}{c}\text { Florets } \\
\text { (no.) }\end{array}$} \\
\hline & Length & Width & & & & & \\
\hline \multicolumn{8}{|l|}{ Shashanbo } \\
\hline VB4x-1 & $6.3 \mathrm{e}^{\mathrm{y}}$ & $5.2 \mathrm{e}$ & $1.2 \mathrm{ab}$ & $1.8 \mathrm{~d}$ & $5.8 \mathrm{~d}$ & $3.7 \mathrm{c}$ & $9.0 \mathrm{ab}$ \\
\hline \multicolumn{8}{|c|}{ Putative hybrids ${ }^{z}$} \\
\hline JM1 & $7.8 \mathrm{bc}$ & $9.4 \mathrm{~b}$ & $0.8 \mathrm{~d}$ & $4.6 \mathrm{a}$ & $7.3 \mathrm{c}$ & $7.4 \mathrm{~b}$ & $11.4 \mathrm{ab}$ \\
\hline JM3 & $9.1 \mathrm{a}$ & $8.1 \mathrm{c}$ & $1.1 \mathrm{bc}$ & $3.2 \mathrm{~b}$ & $10.1 \mathrm{a}$ & $15.7 \mathrm{a}$ & $10.7 \mathrm{ab}$ \\
\hline JM5 & $8.0 \mathrm{ab}$ & $6.7 \mathrm{~d}$ & $1.2 \mathrm{~b}$ & $2.6 \mathrm{c}$ & $8.5 \mathrm{~b}$ & $7.6 \mathrm{~b}$ & $12.0 \mathrm{a}$ \\
\hline \multicolumn{8}{|c|}{ Highbush blueberry } \\
\hline Spartan & $7.4 \mathrm{~cd}$ & $10.1 \mathrm{a}$ & $0.7 \mathrm{~d}$ & $4.9 \mathrm{a}$ & $8.6 \mathrm{~b}$ & $6.6 \mathrm{~b}$ & $8.5 \mathrm{~b}$ \\
\hline
\end{tabular}

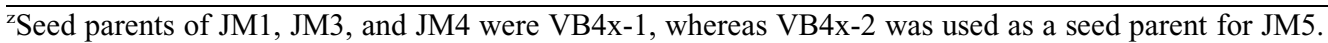

${ }^{y}$ Different letters represent significant differences in Tukey's multiple range test, $5 \%$ level.

Table 3. Comparison of the morphological characteristics of fruit in parents shashanbo and highbush blueberry 'Spartan' and their putative hybrids.

\begin{tabular}{|c|c|c|c|c|c|c|c|c|c|c|}
\hline \multirow[b]{2}{*}{ Strains } & \multirow{2}{*}{$\begin{array}{l}\text { Fruit wt } \\
(\mathrm{g})\end{array}$} & \multicolumn{2}{|c|}{ Fruit size $(\mathrm{mm})$} & \multirow{2}{*}{$\begin{array}{l}\text { Fruit shape index } \\
(\text { diam } / \mathrm{ht})\end{array}$} & \multirow{2}{*}{$\begin{array}{l}\text { Soluble solids } \\
\text { concn }(\%)\end{array}$} & \multicolumn{2}{|c|}{ Seeds (no.) } & \multicolumn{3}{|c|}{ Color of peel ${ }^{\mathrm{w}}$} \\
\hline & & diam & ht & & & Developed & Undeveloped & $\mathrm{L}^{*}$ & $a^{*}$ & $\mathrm{~b}^{*}$ \\
\hline \multicolumn{11}{|l|}{ Shashanbo } \\
\hline VB4x-1 & $0.2 \mathrm{a}^{\mathrm{y}}$ & $7.0 \mathrm{a}$ & $6.4 \mathrm{a}$ & $1.1 \mathrm{ab}$ & $17.2 \mathrm{~b}$ & $2.7 \mathrm{ab}$ & $5.0 \mathrm{a}$ & $34.7 \mathrm{~b}$ & $1.6 \mathrm{~b}$ & 0.9 \\
\hline \multicolumn{11}{|c|}{ Putative hybrids ${ }^{z}$} \\
\hline JM1 & $1.7 \mathrm{c}$ & $14.2 \mathrm{c}$ & $12.9 \mathrm{c}$ & $1.1 \mathrm{a}$ & $15.8 \mathrm{~b}$ & $13.4 \mathrm{~b}$ & $21.3 \mathrm{ab}$ & $25.9 \mathrm{a}$ & $0.0 \mathrm{a}$ & -0.3 \\
\hline JM5 & $0.9 \mathrm{~b}$ & $12.2 \mathrm{~b}$ & $10.8 \mathrm{~b}$ & $1.1 \mathrm{ab}$ & $13.1 \mathrm{ab}$ & $1.8 \mathrm{a}$ & $16.3 \mathrm{a}$ & $27.2 \mathrm{a}$ & $0.5 \mathrm{ab}$ & -0.1 \\
\hline \multicolumn{11}{|c|}{ Highbush blueberry } \\
\hline Spartan & $3.5 \mathrm{~d}$ & $20.2 \mathrm{~d}$ & $14.9 \mathrm{~d}$ & $1.4 \mathrm{c}$ & $11.7 \mathrm{a}$ & $27.8 \mathrm{c}$ & $40.3 \mathrm{~b}$ & $46.7 \mathrm{c}$ & $0.3 \mathrm{a}$ & -8.8 \\
\hline
\end{tabular}

${ }^{\mathrm{z}}$ Seed parents of JM1, JM3, and JM4 were VB4x-1, whereas VB4x-2 was used as a seed parent for JM5.

${ }^{\mathrm{y}}$ Different letters represent significant differences in Tukey's multiple range test, $1 \%$ level.

${ }^{x}$ The fruit of VB4x-2 was not investigated because of poor fruit set.

${ }^{\text {w}}$ Peel color was detected by spectrophotometer at the harvest time; $\mathrm{L}^{*}=$ lightness-darkness parameter, $\mathrm{a}^{*}=$ red-green parameter, $\mathrm{b}^{*}=\mathrm{blue}-$ yellow parameter.

Although the flowering of shashanbo started in early June, 'Spartan' began to bloom in early April. The putative hybrids began to bloom at the end of April or the beginning of May, which is approximately halfway between the bloom dates of their parents (data not shown). Only JM2 did not bloom among the five putative hybrids in 2012. Although the corollas of the 
putative hybrids were significantly larger than that of shashanbo, the size varied among the plants (Table 2). Length of pedicels varied among the putative hybrids, and these were significantly longer than those of shashanbo. Shashanbo and the putative hybrids had pubescence on their petals, receptacles, and pedicels, but 'Spartan' had no pubescence. Bracts were found on the inflorescences of shashanbo and some of the putative hybrids examined (Fig. 2), whereas none of the 'Spartan' inflorescences had bracts.

Although the fruit maturation of 'Spartan' started in early June, shashanbo fruit began to mature in October. In 2012, the putative hybrids began to mature from the middle of July to September, which is approximately halfway between the maturing dates of their parents (data not shown). In addition, the maturing period of the putative hybrids overlapped partially with the end of the ripening period of rabbiteye blueberry in our region. Although the fruit weights of hybrids $(0.9$ to $1.7 \mathrm{~g})$ were less than half that of 'Spartan' (3.5 g), soluble solids concentration of JM1 (15.8\%) and JM4 (15.4\%) was significantly higher than that of 'Spartan' (11.7\%) (Table 3). The number of developed and undeveloped seeds obtained in the fruit of all hybrids was intermediate between parents (Table 3 ). Brightness $\left(\mathrm{L}^{*}\right)$ of the peel as determined by the spectrophotometer showed significant differences between the putative hybrids and 'Spartan' (Table 3). It is noteworthy that the pulp of hybrids was tinged with red as the pulp of shashanbo (Fig. 3). We observed two distinctive types of inflorescence coexisted on one plant in the intersectional hybrid JM1. Inflorescence type exhibited with a large bract (or small leaf), whereas the other type had a small or no bract (Fig. 2).

To confirm the hybridity of these plants, we carried out RAPD analysis on the five putative hybrids and both parents. Polymorphic banding patterns were obtained with six (JM1), five (JM2), four (JM3), two (JM4), and six (JM5) of 40 random primer pairs used for the experiment. As shown in Figure 4A, all plants yielded bands specific to both parents, thus confirming the hybridity of these plants. CAPS analysis of the cytoplasmic DNA regions was then performed to examine their normal maternal inheritance. Although every primer pair amplified the bands satisfactorily, none revealed any polymorphism on the agarose gels. When the PCR products were digested with 19 (cpDNA) and 22 (mtDNA) restriction endonucleases, cpDNA polymorphism was observed in the primer/enzyme combination of trnK-3914F-trnK-2R/Xba (Fig. 4B), and mtDNA polymorphism was observed in the primer/enzyme combination of nad4exon1-nad4exon2/Xba (Fig. 4C). In the present study, all plants had uniform bands that were identical to those of the seed parents, indicating that their cytoplasmic DNA was of maternal origin.

The putative hybrids were analyzed for ploidy levels using a flow cytometer (Table 4). In this analysis, both parents and all seedlings showed tetraploid peaks. The nuclear DNA contents of the putative hybrids [JM1 to JM4 (1.20 to $1.27 \mathrm{pg} / 2 \mathrm{C})$ ] from crosses between VB4x-1 (1.30 pg/2C) and 'Spartan' (1.19 pg/ $2 \mathrm{C})$ were intermediate between those of the parents. In contrast, those of JM5 (1.21 pg/2C) that were obtained from VB4x-2 $(1.11 \mathrm{pg} / 2 \mathrm{C})$ as a seed parent were not significantly different from those of the parents. Furthermore, the chromosome counts of the shoot tips revealed that all of the putative hybrids had 48 chromosomes (Fig. 5).

Four putative hybrids (JM1, JM3, JM4, and JM5) and their parents were examined for pollen stainability. The pollen stainability rates of JM3, JM5, and VB4x-2 were low $(29.8 \%$, $18.3 \%$, and $29.5 \%$, respectively), and those of JM1 and JM4 were high (57.4\% and 61.3\%, respectively) (Table 5). Likewise, VB4x-1 and 'Spartan' showed pollen stainability of $54.0 \%$ and $74.0 \%$, respectively. The putative hybrids that had low stainability, JM3 and JM5, had shriveled pollen with abnormal shapes that failed to stain with acetocarmine.

\section{Discussion}

This is the first report of the successful production of hybrids between native species of genus Vaccinium to Japan and a blueberry cultivar. In this study, the crosses between the tetraploid colchicine-induced shashanbo and the tetraploid highbush blueberry 'Spartan' produced tetraploid hybrids. Within Vaccinium section Cyanococcus, colchicine-induced tetraploid plants can be readily crossed with other species of the same ploidy level (Chavez and Lyrene, 2009). When diploid Vaccinium elliottii was crossed as a pollen parent with tetraploid cultivars of southern highbush blueberry, 0.01 seedlings per pollinated flower were obtained, whereas 3.86 seedlings per pollinated flower were obtained when autotetraploid V. elliottii FL519 was used as a pollen parent (Dweikat and Lyrene, 1991). Lyrene (2011) and Lyrene and Olmstead (2012) also produced intersectional hybrids by crossing tetraploids. Successful production of intersectional hybrids in the present study can also be attributed to the use of the same ploidy level parents in the cross.

Among the 66 seedlings obtained from the present intersectional crosses, we observed the genetic characters of five putative hybrid plants. Both ploidy analysis using flow cytometry and chromosome counting revealed that they were tetraploid. Flow cytometric analysis of the remaining 61 seedlings revealed that they were also tetraploid (data not shown). Because these 61 seedlings were grown without grafting, most of them have not yet reached the flowering stage. The plant architecture and leaf morphology of these 61 evergreen seedlings were similar to those of shashanbo and so far only three flowers bloomed that closely resembled those of shashanbo. Thus, it is possible that these tetraploid seedlings were derived from self-pollination based on the morphological characteristic. Therefore, further investigation is necessary to determine their hybridity.

The morphological characteristics of the hybrids were intermediate between those of evergreen shrub shashanbo and deciduous highbush blueberry 'Spartan'. Hybrids started to bloom after the end of the flowering period of 'Spartan'. Similar to the late flowering of Vavvinium arboreum (section Batodendron) (Chavez and Lyrene, 2010), the late flowering of our hybrids could prevent crop loss as a result of late freeze that affects currently cultivated blueberry. Lyrene (1997) found that for genotype MIK (Vaccinium darrowi $\times V$. arboreum) and southern highbush blueberry cultivars, the time of ripening ranged from as early as that of the earliest southern highbush blueberry cultivar to later than that of the latest rabbiteye blueberry cultivar. Ripening periods of hybrids were later than that of highbush blueberry 'Spartan', which was approximately the same ripening period as that of late cultivars of rabbiteye blueberry in the southern part of Japan. One of the serious problems with blueberry culture in Japan is that the ripening period of the main highbush blueberry cultivars coincides with the rainy season (June and July), making it very difficult to produce high-quality 
OPA-7

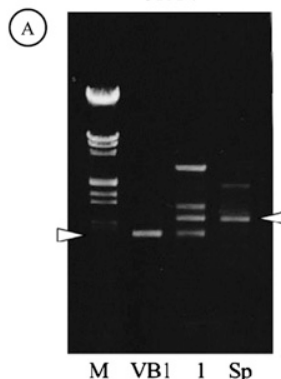

OPH-14

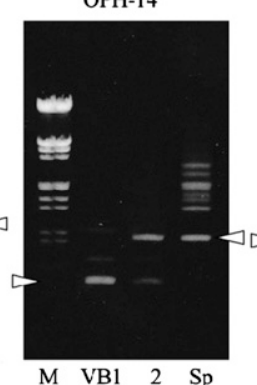

OPH-16

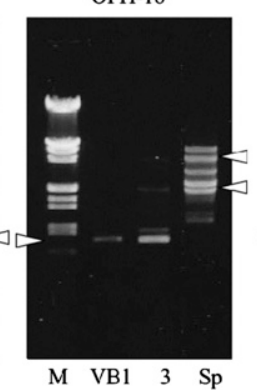

OPA- 8

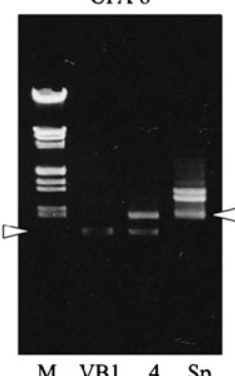

M $\quad$ VB1 4 Sp

trnK-39I4F-trnK-2R/Xba I

(B)
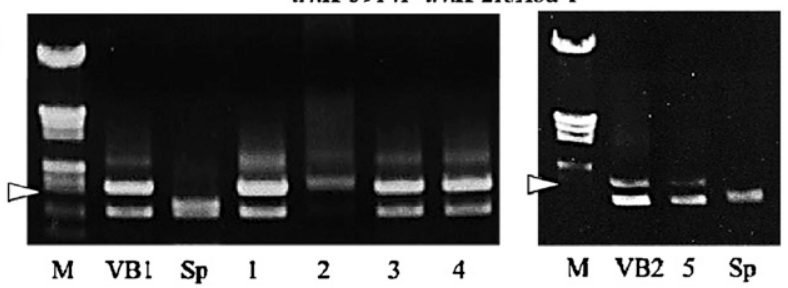

nad4cxon1-nad4exon2/Xha I
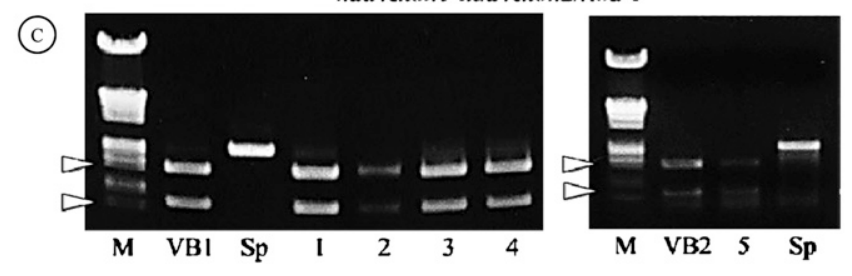

Fig. 4. RAPD and CAPS analyses among putative intersectional hybrids in Vaccinium. (A) RAPD analysis of the seedlings obtained from the cross between shashanbo and highbush blueberry. (B) Restriction pattern of the $X b a \mathrm{I}$-digested $\operatorname{trn} K-3914 F-\operatorname{trn} K-2 R$ regions of chloroplast genomes. (C) Restriction pattern of the $X b a \mathrm{I}$-digested nad4exon1- nad4exon2 regions of mitochondrial genomes; $\mathrm{M}=100$-bp ladder marker; VB1 and VB2 = shashanbo; 1-5 = putative intersectional hybrids JM1-JM5; Sp = highbush blueberry 'Spartan'. Arrowheads indicate the bands specific to both $(\mathbf{A})$ or one $(\mathbf{B}-\mathbf{C})$ parent. RAPD = random amplified polymorphic DNA; CAPS $=$ cleaved amplified polymorphic sequence.

Table 4. Nuclear DNA content in parents shashanbo and highbush blueberry 'Spartan' and their putative hybrids as determined by flow cytometry.

\begin{tabular}{lc}
\hline Strains & $\begin{array}{c}\text { Nuclear DNA content } \\
(\mathrm{pg} / 2 \mathrm{C})\end{array}$ \\
\hline Shashanbo & $1.30 \mathrm{a}^{\mathrm{y}}$ \\
VB4x-1 & $1.11 \mathrm{e}$ \\
VB4x-2 & \\
Putative hybrids & $1.23 \mathrm{ab}$ \\
JM1 & $1.27 \mathrm{ab}$ \\
JM2 & $1.20 \mathrm{bc}$ \\
JM3 & $1.22 \mathrm{ab}$ \\
JM4 & $1.21 \mathrm{abc}$ \\
JM5 & \\
Highbush blueberry & $1.19 \mathrm{bc}$ \\
Spartan &
\end{tabular}

zSeed parents of JM1 to JM4 were VB4X-1, whereas VB4x-2 was used as a seed parent for JM5.

'Different letters represent significant differences in Tukey's multiple range test, $5 \%$ level.

fruit (Tamada, 1996). Consequently, hybrids that ripen after the conclusion of the rainy season are important genetic resources. The fall production of blueberries using hybrids created in this study and subsequent generations could extend the harvest season and
$\mathrm{OPH}-17$

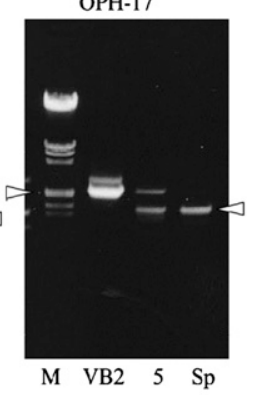

allow off-season fruit production during periods of high market prices.

Recently, breeding programs have focused on fruit quality, especially improving nutritional value and obtaining cultivars with enhanced levels of bioactive substances (Scalzo et al., 2005; Wang et al., 2012). The high antioxidant activities in fruit are largely attributed to phenolic compounds such as anthocyanins and other flavonoid compounds (Wang et al., 2012). Anthocyanins are present in both the peel and pulp of bileberry (Vaccinium myrtillus) but mainly in the peel of blueberry (Lee and Wrolstad, 2004; Ribera et al., 2010; Riihinen et al., 2008) and the content of anthocyanins is lower in blueberry than in bilberry on a flesh weight basis (Riihinen et al., 2008). One way to increase the antioxidant activity of blueberries is to develop commercial types that have these compounds in the pulp. In this study, the pulp of hybrids was tinged with red as is the case in shashanbo parental types. Although the fruit weight of hybrids was less than half that of the fruit of 'Spartan', soluble solids concentration of two hybrids was higher than that of 'Spartan'. The hybrids of the present research are expected to become breeding materials for new cultivars with higher sugar content and more abundant functional components than those of existing blueberry cultivars.

In addition to the overall intermediate characteristics in morphological and physiological traits of the putative hybrids, the results of RAPD analysis proved that the seedlings obtained in this study were hybrids. In the majority of angiosperms, nuclear DNA is inherited biparentally, and cpDNA is inherited maternally (Tsukaya et al., 2003; Yang et al., 2000). However, in the family Ericaceae, biparental inheritance of cytoplasmic DNA was reported (Ureshino, 2008). Therefore, in the present study, heredity of the cytoplasm in the hybrids was investigated. The results of CAPS analysis indicated that the cytoplasmic DNA of the intersectional hybrids was of maternal origin. This result agreed with findings of Haghighi and Hancock (1992) that the mtDNA of interspecific hybrids obtained from the cross between $V$. darrowii and $V$. corymbosum was of maternal origin.

Variation of pollen stainability was found in the intersectional hybrids in this study and this is consistent with other studies. Chavez and Lyrene (2010) found pollen stainability of intersectional hybrids was much lower (5.8\%) than those of parents $V$. darrowii $(95.8 \%)$ and $V$. arboreum $(92.2 \%)$ and Brooks and Lyrene (1998) also found that pollen stainability of $\mathrm{F}_{1}(V$. darrowi $\times V$. arboreum $)$ hybrids averaged only $0.9 \%$. Low pollen fertility of these intersectional hybrids was the result of the infrequency of normal bivalent pairing between the two chromosome sets and numerous meiotic abnormalities from 

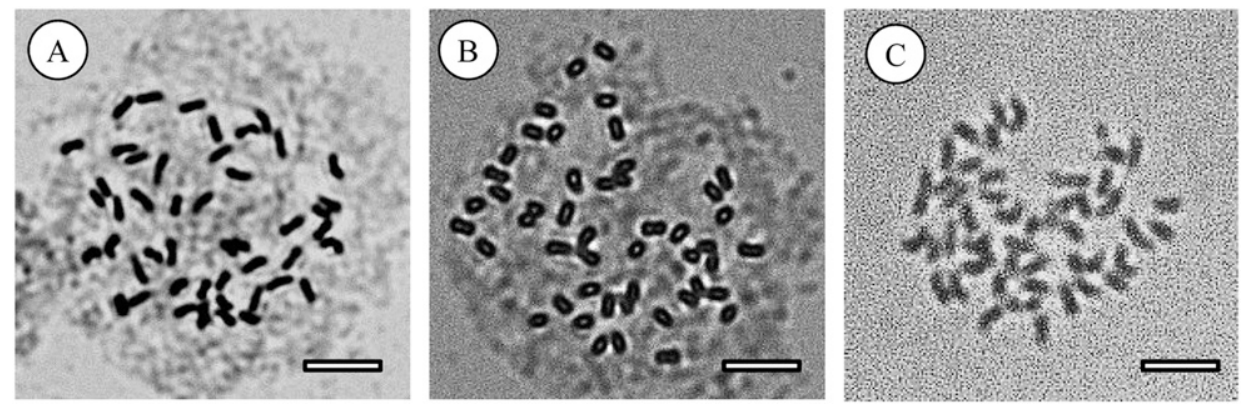

that could be easily backcrossed to highbush blueberry cultivars to obtain the next generations.

In conclusion, we succeeded in crossing section Bracteata and section Cyanococcus of Vaccinium and obtaining intersectional hybrid plants. These hybrids could be useful breeding materials for producing new cultivars with high sugar content, abundant phytochemicals, and extensive environmental adaptability as well as late flowering and ripening. Further investigations, including studies of the meiotic chromosome behavior, female fertility,

Table 5. Comparison of the pollen stainability in parents shashanbo and highbush blueberry 'Spartan' and their putative hybrids.

\begin{tabular}{lc}
\hline Strains & $\begin{array}{c}\text { Pollen stainability } \\
(\%)^{\mathrm{y}}\end{array}$ \\
\hline $\begin{array}{l}\text { Shashanbo } \\
\text { VB4x-1 }\end{array}$ & $54.0 \mathrm{~b}^{\mathrm{x}}$ \\
VB4x-2 & $29.5 \mathrm{c}$ \\
Putative hybrids & \\
JM1 & $57.4 \mathrm{~b}$ \\
JM3 & $29.8 \mathrm{c}$ \\
JM4 & $61.3 \mathrm{~b}$ \\
JM5 & $18.3 \mathrm{~d}$ \\
Highbush blueberry & \\
Spartan & $74.0 \mathrm{a}$ \\
\hline
\end{tabular}

${ }^{\mathrm{z} S e e d}$ parents of JM1, JM3, and JM4 were VB4x-1, whereas VB4x-2 was used as a seed parent for JM5.

${ }^{y}$ Well-filled and evenly stained pollen grains/total pollen grains examined $\times 100$.

${ }^{x}$ Different letters represent significant differences in Tukey's multiple range test, $1 \%$ level.

chromosome structural differentiation between the two sections of the genus (Brooks and Lyrene, 1995, 1998; Chavez and Lyrene, 2010; Lyrene, 1991). Although intersectional diploid hybrids in Vaccinium are normally sterile, intersectional tetraploid hybrids produced by the cross between autotetraploid species of Vaccinium can be fertile, presumably as a result of autosyndetic chromosome pairing (Lyrene and Olmstead, 2012) and Rousi (1963) produced fertile hybrids between tetraploid $V$. uliginosum (section Vaccinium) and tetraploid $V$. corymbosum. Furthermore, the crosses of colchicine-induced tetraploid $V$. arboreum with tetraploid highbush blueberry cultivars and with tetraploid $V$. myrsinites (section Cyanococcus) produced vigorous and fertile tetraploid hybrids (Lyrene and Olmstead, 2012). Lyrene et al. (2003) reported that the surprisingly high fertility of $\mathrm{F}_{1}$ hybrids between tetraploid $V$. corymbosum and tetraploid $V$. uliginosum (Rousi, 1966) is most easily understood if both parental species are autopolyploid and chromosome pairing in the allopolyploid $\mathrm{F}_{1}$ is from autosyndesis. We obtained hybrids by the crosses of parents with autopolyploidy, and they may behave as amphidiploids might become amphidiploidy, because the fertility of hybrids was high. In addition, Lyrene (2011) and Rousi (1963) reported the difference of pollen fertility among the strains in the intersectional tetraploid hybrids. This variability of pollen fertility was also indicated in our hybrids, and several hybrids had high fertility fruit characteristics, and growth of their own roots, are necessary. Moreover, selection of the hybrid from remaining evergreen seedlings is necessary to expand the gene pool for our breeding program.

\section{Literature Cited}

Atkinson, R., K. Jong, and G. Argent. 1995. Cytotaxonomic observations in tropical Vaccinieae (Ericaceae). Bot. J. Linn. Soc. 117:135145.

Ballington, J.R. 1980. Crossability between subgenus Cyanococcus (Gray) Klotzsch and subgenus Polycodium (Raf.) Sleumer in Vaccinium. HortScience 15:419 (abstr.).

Ballington, J.R. 2001. Collection, utilization, and preservation of genetic resources in Vaccinium. HortScience 36:213-220.

Brooks, S.J. and P.M. Lyrene. 1995. Characteristics of sparkleberry $\times$ blueberry hybrids. Proc. Florida State Hort. Soc. 108:337-339.

Brooks, S.J. and P.M. Lyrene. 1998. Derivatives of Vaccinium arboreum $\times$ Vaccinium section Cyanococcus: II. Fertility and fertility parameters. J. Amer. Soc. Hort. Sci. 123:997-1003.

Chavez, D.J. and P.M. Lyrene. 2009. Production and identification of colchicine-derived tetraploid Vaccinium darrowii and its use in breeding. J. Amer. Soc. Hort. Sci. 134:356-363.

Chavez, D.J. and P.M. Lyrene. 2010. Hybridization of two diploid Vaccinium section Cyanococcus species with diploid Vaccinium arboreum in section Batodendron. Euphytica 171:263-272.

Cheng, Y.J., W.W. Guo, and X.X. Deng. 2002. Inheritance of organelle genomes of the somatic hybrid between Cleopatra mandarin (Citrus reticulata) and Flying dragon (Poncirus trifoliata). Acta Genetica Sinica 29:364-369.

Darrow, G.M. and W.H. Camp. 1945. Vaccinium hybrids and the development of new horticultural material. Bull. Torrey Bot. Club 72:1-21.

Darrow, G.M., W.H. Camp, F.E. Fischer, and H. Derman. 1944. Chromosomes in Vaccinium and related groups. Bull. Torrey Bot. Club 71:498-506.

Doyle, J. and J.L. Doyle. 1987. A rapid DNA isolation procedure for small quantities fresh leaf tissue. Phytochem. Bul. 19:11-15.

Dumolin-Lapegue, S., M.H. Pemonge, and R.J. Petit. 1997. An enlarged set of consensus primers for the study of organelle DNA in plants. Mol. Ecol. 6:393-397.

Dweikat, I.M. and P.M. Lyrene. 1991. Induced tetraploidy in a Vaccinium elliottii clone facilitates crossing with cultivated highbush blueberry. J. Amer. Soc. Hort. Sci. 116:1063-1066.

Fukui, K. 1996. Plant chromosome at mitosis, p. 1-17. In: Fukui, K. and S. Nakayama (eds.). Plant chromosome, Laboratory methods. CRC Press, Boca Raton, FL.

Haghighi, K. and J.F. Hancock. 1992. DNA restriction fragment length variability in the genomes of highbush blueberry. HortScience $27: 44-47$. 
Hirai, M., S. Yoshimura, T. Ohsako, and N. Kubo. 2010. Genetic diversity and phylogenetic relationships of the endangered species Vaccinium sieboldii and Vaccinium ciliatum (Ericaceae). Plant Syst. Evol. 287:75-84.

Iwagaki, H., T. Tamada, S. Ishikawa, and H. Koike. 1977. The present status of blueberry work and wild Vaccinium species in Japan. Acta Hort. 61:331-334.

Karizumi, N. 1979. Illustrations of tree roots. Seibundo Shinkosha, Tokyo, Japan [in Japanese].

Kunitake, H., H. Tsuda, R. Takagi, Y. Ohono, Y. Kuroki, K. Yoshioka, T. Kage, T. Ito, and H. Komatsu. 2006. Possibility of wild blueberry shashanbo (Vaccinium bracteatum Thunb.) as a rootstock for cultivation of northern highbush blueberry in warm region. Hort. Res. (Japan) 5:105-110 [in Japanese with English abstract].

Lee, J. and R.E. Wrolstad. 2004. Extraction of anthocyanins and polyphenolics from blueberry processing waste. J. Food Sci. 69:564-573.

Lloyd, G. and B. McCown. 1980. Commercially feasible micropropagation of mountain laurel, Kalmia latifolia, by use of shoot-tip culture. Comb. Proc. Int. Plant Prop. Soc. 30:421-427.

Luby, J., J.R. Ballington, A.D. Draper, K. Pliszka, and M.E. Austin. 1991. Blueberries and cranberries (Vaccinium). Acta Hort. 290:391-456.

Lyrene, P.M. 1991. Fertile derivatives from sparkleberry $\times$ blueberry crosses. J. Amer. Soc. Hort. Sci. 116:899-902.

Lyrene, P.M. 1997. Value of various taxa in breeding tetraploid blueberries in Florida. Euphytica 94:15-22.

Lyrene, P.M. 2011. First report of Vaccinium arboreum hybrids with cultivated highbush blueberry. HortScience 46:563-566.

Lyrene, P.M. and J.R. Ballington. 1986. Wide hybridization in Vaccinium. HortScience 21:52-57.

Lyrene, P.M. and J.W. Olmstead. 2012. The use of inter-sectional hybrids in blueberry breeding. Intl. J. Fruit Sci. 12:269-275.

Lyrene, P.M., N. Vorsa, and J.R. Ballington. 2003. Polyploidy and sexual polyploidization in the genus Vaccinium. Euphytica 133:27-36. Murashige, T. and F. Skoog. 1962. A revised medium for rapid growth and bioassay with tobacco tissue cultures. Physiol. Plantarum 15:473497.

Ollitraut, P., D. Dambier, F. Luro, and C. Duperray. 1994. Nuclear genome size variations in Citrus. Fruit 49:390-393.

Ribera, A.E., M. Reyes-Diaz, M. Alberdi, G.E. Zuñiga, and M.L. Mora. 2010. Antioxidant compounds in skin and pulp of fruit change among genotypes and maturity stages in highbush blueberry ( $\mathrm{Vacci}$ nium corymbosum L.) growing in southern Chile. J. Soil Sci. Plant Nutr. 10:509-536.
Riihinen, K., L. Jaakola, S. Karenlampi, and A. Hohtola. 2008. Organspecific distribution of phenolic compounds in bilberry (Vaccinium myrtillus) and 'Northblue' blueberry (Vaccinium corymbosum $\times$ V. angustifolium). Food Chem. 110:156-160.

Rousi, A. 1963. Hybridization between Vaccinium uliginosum and cultivated blueberry. Ann. Agr. Fenniae 2:12-18.

Rousi, A. 1966. The use of north-European Vaccinium species in blueberry breeding. Acta Agr. Scandinavica 16(suppl):50-54.

Scalzo, J., A. Politi, N. Pellegrini, B. Mezzetti, and M. Battino. 2005. Plant genotype affects total antioxidant capacity and phenolic contents in fruit. Nutrition 21:207-213.

Tamada, T. 1996. Blueberry culture and research in Japan. J. Small Fruit Viticult. 3:227-241.

Tetsumura, T., Y. Matsumoto, M. Sato, C. Honsho, K. Yamashita, H. Komatsu, Y. Sugimoto, and H. Kunitake. 2008. Evaluation of basal media for micropropagation of four highbush blueberry cultivars. Sci. Hort. 119:72-74.

Tsukaya, H., T. Fukuda, and J. Yokoyama. 2003. Hybridization and introgression between Callicarpa Japonica and C. mollis (Verbenaceae) in central Japan, as inferred from nuclear and chloroplast DNA sequence. Mol. Ecol. 12:3003-3011.

Ureshino, K. 2008. Study of cross incompatibility between evergreen and deciduous azaleas. J. Jpn. Soc. Hort. Sci. 77:1-6.

Ureshino, K. and I. Miyajima. 2002. The study on the relationship between leaf colors and ptDNA inheritance in intersectional cross of Rhododendron kiusianum $\times R$. Japonicum $\mathrm{f}$. flavum, resulting in an unexpected triploid progeny. J. Jpn. Soc. Hort. Sci. 71:214-219.

Wang, S.Y., H. Chen, M.J. Camp, and M.K. Ehlenfeldt. 2012. Flavonoid constituents and their contribution to antioxidant activity in cultivars and hybrids of rabbiteye blueberry (Vaccinium ashei Reade). Food Chem. 132:855-864.

Williams, J.G.K., A.R. Kubelik, K.J. Lival, J.M. Rafalski, and S.V. Tingey. 1990. DNA polymorphisms amplified by arbitrary primers are useful as genetic markers. Nucleic Acids Res. 18:6531-6535.

Yahata, M., S. Harusaki, H. Komatsu, K. Takami, H. Kunitake, T. Yabuya, K. Yamashita, and P. Toolapong. 2005. Morphological characterization and molecular verification of a fertile haploid pummelo (Citrus grandis Osbeck). J. Amer. Soc. Hort. Sci. 130:34-40.

Yamazaki, T. 1989. Ericaceae, p. 122-156. In: Satake, Y., H. Hara, S. Watari, and T. Tominari (eds.). Wild flowers of Japan, woody plants, Vol. 2. Heibonsha, Tokyo, Japan [in Japanese].

Yang, T.W., Y.A. Yang, and Z.G. Xiong. 2000. Paternal inheritance of chloroplast DNA in the genus Larrea (Zygophyllaceae). Amer. J. Bot. 87:1452-1458. 